\title{
Transthoracic versus transhiatal esophagectomy - influence on patient survival
}

\author{
Mariusz Łochowski, Barbara Łochowska, Józef Kozak \\ Department of Thoracic Surgery, Memorial Copernicus Hospital, Medical University of Lodz, Lodz, Poland
}

Gastroenterology Rev 2017; 12 (2): 118-121

DOI: https://doi.org/10.5114/pg.2016.64609

Key words: cancer of esophagus, transthoracic surgery, transhiatal surgery, survival length.

Address for correspondence: Mariusz tochowski MD, PhD, Department of Thoracic Surgery, Memorial Copernicus Hospital, Medical University of Lodz, 62 Pabianicka St, 93-513 Lodz, Poland, fax: +48 4268950 10, e-mail: marilo@op.pl

\begin{abstract}
Aim: To evaluate the survival of patients after surgery of the esophagus/cardia using the transthoracic and transhiatal methods.

Material and methods: In the years 2007-2011, 102 patients were radically treated for cancer of the esophagus/cardia: 24 women and 78 men at the average age of 59.5. There were 38 transthoracic procedures and 64 transhiatal procedures. All patients had a conduit made from the stomach, led through lodges in the esophagus and combined with the stump of the esophagus in the neck following the Collard method. Two-pole lymphadenectomies were performed in all patients.

Results: Patients after transthoracic procedures had statistically more $(p<0.05)$ lymph nodes removed than patients after transhiatal procedures. The 5 -year survival rates in transhiatal and transthoracic procedures did not statistically differ, being $8 \%$ and $0 \%$ respectively. The length of patient survival was influenced by metastases in the nearby lymph nodes $(p<0.0001)$ and the presence of adenocarcinoma.

Conclusions: Surgical access (transhiatal and transthoracic surgery) does not affect the 5-year survival rates. Transhiatal surgery allows a greater number of lymph nodes to be removed. The main factor influencing the 5 -year survival rate is the presence of metastases in the nearby lymph nodes.
\end{abstract}

\section{Introduction}

Esophageal resection of cancer of the esophagus or the oesophago-gastric junction with one-time reconstruction is the standard surgical treatment. Controversies exist over the surgical approach: some surgeons choose transthoracic esophagectomy (TTE), while others prefer transhiatal esophagectomy (THE).

\section{Aim}

The aim of the study was to evaluate the survival of patients with cancer of the esophagus/cardia treated with transthoracic and transhiatal surgery.

\section{Material and methods}

The analysis covered 102 patients (24 women and 78 men) aged 19-75 (average age of 59.5) treated radically due to cancer of the esophagus/cardia in the last 5 years. Patients were subjected to two types of surgery: transthoracic (the McKeown method) in
38 and transhiatal (the Orringer method) in 64 cases. In all patients, the stomach, moved through the posterior mediastinum, was used as a substitute for the esophagus (conduit). The fusion of the stump of the proximal part of the esophagus (approx. $2 \mathrm{~cm}$ ) with the conduit was done through a left-sided cervicotomy using the semi-mechanical technique (side-to-side applying the Collard method). The gavage, introduced in the esophagus through the nose, was transferred to the conduit through the fusion. The surrounding area of the fusion was drained with a Redon drain. Nutritional jejunostomy was produced in the proximal part of the small intestine. Polymyotomy was performed in the majority of patients. Clot and bacterial prevention was provided. In the first 2 days after surgery patients were fed intravenously and from the second day on through the intestine with standard nutrition preparations. In the postoperative period (day 6) a radiological investigation was conducted with the 
Table I. Comparison of patients qualified for excision of the esophagus using the transthoracic (TTE) and transhiatal (THE) method

\begin{tabular}{|c|c|c|c|}
\hline Tested factor & $\begin{array}{c}\text { TTE } \\
(n=38)\end{array}$ & $\begin{array}{c}\text { THE } \\
(n=64)\end{array}$ & $\begin{array}{c}\text { TTE/THE } \\
p\end{array}$ \\
\hline \multicolumn{4}{|l|}{ Location of the tumor: } \\
\hline Neck & - & - & \\
\hline Upper chest & 4 & - & - \\
\hline Middle chest & 28 & - & - \\
\hline Lower chest & 6 & 16 & - \\
\hline Abdominal/cardia & - & 48 & - \\
\hline \multicolumn{4}{|l|}{ Histological type: } \\
\hline Squamous cell carcinoma & 32 & 23 & $<0.0001$ \\
\hline Adenocarcinoma & 6 & 41 & \\
\hline
\end{tabular}

administration of a contrast medium (gastrografin) and evaluation of the healing of the anastomosis in the neck (anastomotic tightness). In the study group, 47 patients underwent postoperative radio-chemotherapy (18 after TTE and 29 after THE).

A retrospective study assessing the survival of patients after TTE and THE procedures was carried out. The analysis considered the following factors: histopathological diagnosis, tumor location, severity of cancer and radical nature of the treatment.

\section{Statistical analysis}

The results of the study were recorded in an Excel spreadsheet of the MS Office 2007 software package and thereafter subjected to a statistical analysis using the following tests: $\chi^{2}$ test, Shapiro-Wilk and Mann-Whitney tests, and Gehan's generalization of the Wilcoxon test. For all statistical comparisons, a statistically significant difference was accepted at the level of $p<0.05$.

\section{Results}

Patients qualified for an open (transthoracic) procedure had a higher clinical stage in the TNM classification (63\% at stage III) with a tumor located closer to the esophagus. Patients qualified for a transhiatal procedure had lower clinical stage (53\% at stage III) with a tumor located closer to the cardia. Squamous tumors predominated in transthoracic procedures (84\% of cases), while adenocarcinoma was more common (64\% of cases) in transhiatal procedures, which was statistically significant at $p<0.0001$ (Table I). R0 resection was achieved in $95 \%$ of patients after TTE and $86 \%$ after THE. R2 resection was observed solely in the group of patients after THE (6\%). Statistical-
Table II. Oncological completeness of oesophageal excision using the transthoracic (TTE) and transhiatal (THE) method

\begin{tabular}{lccc} 
Tested factor & $\begin{array}{c}\text { TTE } \\
(n=38)\end{array}$ & $\begin{array}{c}\text { THE } \\
(n=64)\end{array}$ & $\begin{array}{c}\text { TTE/THE } \\
\boldsymbol{p}\end{array}$ \\
\hline Resection: & $36(95 \%)$ & $55(86 \%)$ & \\
\hline R0 & $2(5 \%)$ & $5(8 \%)$ & NS \\
\hline R1 & 0 & $4(6 \%)$ & \\
\hline R2 & 1 & 5 & \\
\hline Simplified TNM: & 13 & 25 & NS \\
\hline I & 24 & 34 & \\
\hline III & $10 \pm 5$ & $8 \pm 4$ & $<0.05$ \\
\hline $\begin{array}{l}\text { Number of removed lymph } \\
\text { nodes }\end{array}$ & & &
\end{tabular}

ly more $(p<0.05)$ lymph nodes were removed during TTE than after THE (Table II). The median survival rates in TTE and THE were 34.4 and 35.6 months respectively at $p=0.76$. The 5 -year survival rates in TTE and THE were $0 \%$ and $8 \%$ respectively $(p=0.76)$ (Figure 1). The presence of metastases to the regional lymph nodes had an impact on the 5 -year survival rates in each type of surgery (Figure 2 ). The risk ratio was 1.34. The diagnosis of adenocarcinoma significantly shortened the length of survival in patients after TTE surgery $(p<0.01)$ (Figure 3$)$. There was no correlation between the location of a tumor and radical nature of the treatment and 5-year survival rates. In 47 patients subjected to supplementary treatment (18 after TTE and 29 after THE), an effect of the treatment on distant survival was not found $(p>0.05)$.

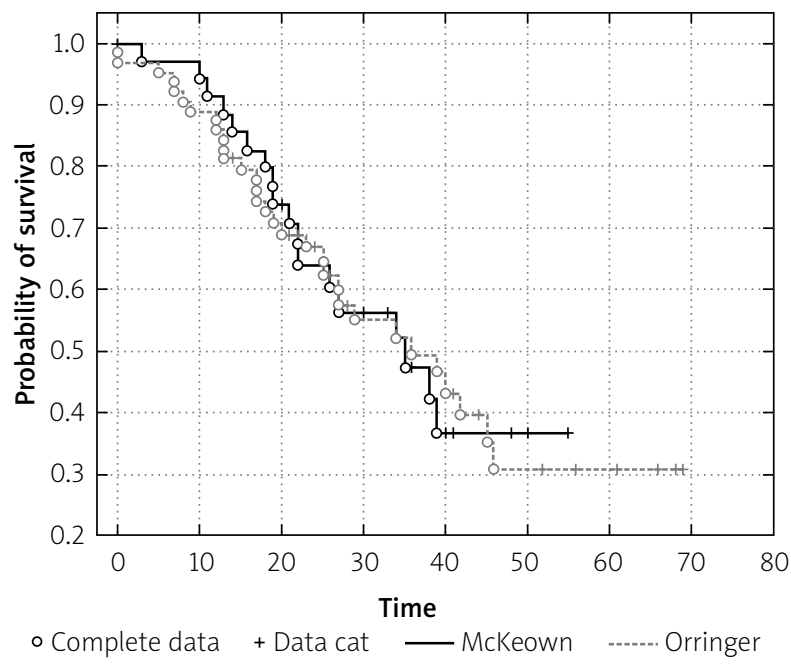

Figure 1. The probability of survival by KaplanMeier curves after the TTE and THE surgery $(p=0.76)$ 


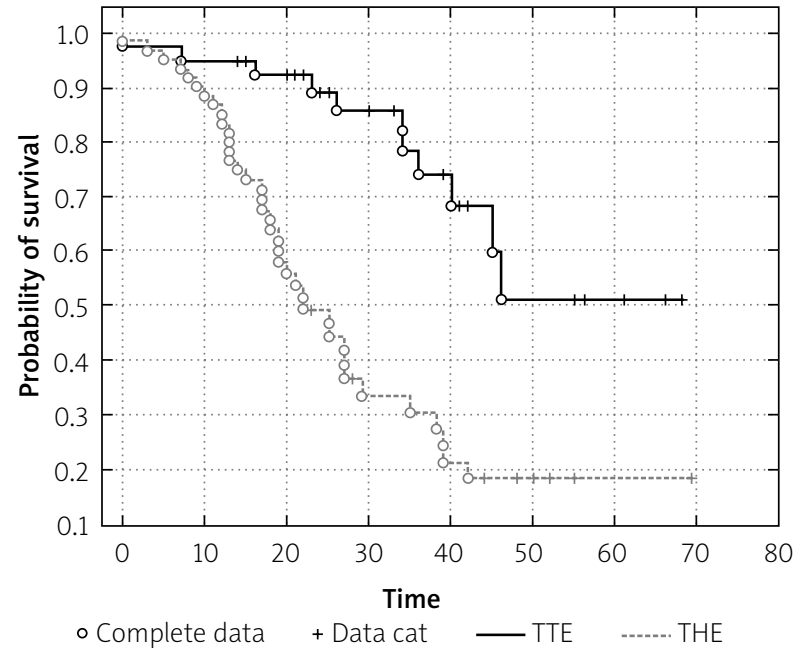

Figure 2. The probability of survival by KaplanMeier curves after the TTE and THE surgery $(p=0.00002)$

\section{Discussion}

Transhiatal and transthoracic resections are currently the standard in the surgical treatment of cancer of the esophagus or cardia. Both techniques have their supporters and opponents, while the question "what is the best way of treating cancer of the esophagus and cardia?" remains to be answered and leads to many discussions and publications in the whole world. Patients qualified for TTE have a tumor, which is rarely an adenocarcinoma, located in the upper chest and middle esophagus section. Transhiatal esophagectomy procedures are performed in patients in whom a tumor, which is most often adenocarcinoma, is located in the lower chest section and cardia [1, 2]. The prognosis depends on the type of tumor, its location, surgical completeness RO and severity of the tumor (pTNM), and is reflected in the length of survival [3]. A meta-analysis of more than 7500 patients published in 2001 did not show any significant differences in the 5-year survival rates between TTE and THE (23\% vs. $21.7 \%$ ) [4]. Similar data were published by Barreto and Posner in 2010, showing a 25\% 5-year survival rate for both surgical techniques [2]. Significant differences in the survival of patients occur when the histopathological type of a tumor is considered. In a study on 2000 patients, Orringer et al. observed statistically significantly $(p<0.0001)$ longer survival of patients with adenocarcinoma after THE [5], while Hulscher et al. obtained a higher 5-year survival rate in patients with the same type of tumor after transhiatal surgery in comparison with the transthoracic technique (39\% vs. $27 \%$ ) [6]. Controversial test results were presented by Gockel et al. In the analysis of 424 patients with ad-

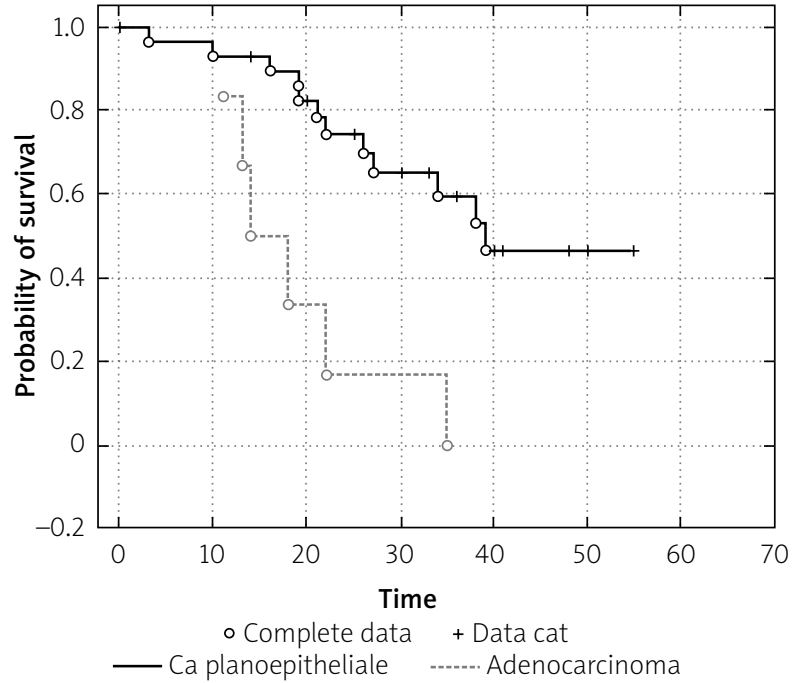

Figure 3. The probability of survival by KaplanMeier curves after the TTE surgery depending on the histopathological diagnosis

enocarcinoma subjected to THE and TTE, they showed that the prognosis depends only on the size of a tumor ( $p T)$ and presence of distant metastases ( $p M)$. The presence of metastases to lymph nodes $(\mathrm{pN})$ does not influence the length of survival for both the procedures [7]. In our study, we observed significantly shorter survival of patients $(p<0.01)$ operated on due to adenocarcinoma using the TTE technique. In the case of squamous cell carcinoma, Junginger et al. found that the prognosis is better if surgery is performed from the transthoracic access. The number of lymph nodes removed during surgery influences the study results [8]. The TTE technique allows for the extensive removal of the mediastinal lymph nodes $[1-4,9$, 10]. Independent studies showed a significantly higher number of lymph nodes removed during TTE compared to THE and the impact on 5-year survival $[1,3,10]$. In our study, we observed a statistically significantly $(p<0.05)$ greater number of lymph nodes removed from the transthoracic access. The presence of metastases in the lymph nodes ( $\mathrm{pN}$ ) affected the survival. The application of post-surgery radio-chemotherapy did not influence the length of survival $[11,12]$. The analysis of 5-year survival conducted on our material confirmed those reports.

\section{Conclusions}

Surgical access (transhiatal and transthoracic surgery) does not influence the 5-year survival rate. Transhiatal surgery allows a greater number of lymph nodes to be removed. The most important factor influencing the 5 -year survival is the presence of metastases in the nearby lymph nodes. 


\section{Conflict of interest}

The authors declare no conflict of interest.

\section{References}

1. Pennathur A, Zhang J, Chen H, et al. The "best operation" for esophageal cancer. Ann Thorac Surg 2010; 89: 2163-7.

2. Barreto JC, Posner MC. Transhiatal versus transthoracic esophagectomy for esophageal cancer. World J Gastroenterol 2010; 16: 3804-10.

3. Donohoe CL, O'Farrell NJ, Ravi N, et al. Evidence-based selective application of transhiatal esophagectomy in a high-volume esophageal centre. World J Surg 2012; 36: 98-103.

4. Orringer MB. Transhiatal esophagectomy. Pearson's thoracic and esophageal surgery. Churchill Livingstone Elsevier, Philadelphia 2008; 563-83.

5. Orringer MB, Marshall B, Chang AC, et al. Two thousand transhiatal esophagectomies: changing trends, lessons learned. Ann Surg 2007; 246: 363-74.

6. Hulscher JBF, van Sandick JW, de Boer AGEM, et al. Extended transthoracic resection compared with limited transhiatal resection for adenocarcinoma of the esophagus. N Engl J Med 2002; 347: 1662-9.

7. Gockel I, Heckhoff S, Messow CM, et al. Transhiatal and transthoracic resection in adenocarcinoma of the esophagus: does the operative approach have an influence on the long-term prognosis? World J Surg Oncol 2005; 3: 40.

8. Junginger T, Gockel I, Heckhoff S. A comparison of transhiatal and transthoracic resections on the prognosis in patients with squamous cell carcinoma of the oesophagus. Eur J Surg Oncol 2006; 32: 749-55.

9. Dawies AR, Forshaw MJ, Khan AA, et al. Transhiatal esophagectomy in a high volume institution. World I Surg Oncol 2008; 6: 88-96.

10. Colvin H, Dunning J, Khan OA. Transthoracic versus transhiatal esophagectomy for distal esophageal cancer: which is superior? Interact Cardio Vasc Surg 2011; 12: 265-9.

11. Hong JC, Murphy JD, Wang SJ, et al. Chemotherapy before and after surgery for locally advanced esophageal cancer. A SEER - Medicare analysis. Ann Surg Oncol 2013; 20: 3999-4007.

12. Shridhar R, Imani-Shikhabadi R, Davis B, et al. Curative treatment of esophageal cancer; an evidence based review. J Gastrointest Cancer 2013; 44: 375-84.

Received: 10.05 .2015

Accepted: 24.12 .2015 